Eskişehir Osmangazi Üniversitesi iißBF Dergisi

Aralık 2020, C. 15, S. 3, $1043-1060$

Başvuru : 15.02 .2019

Kabul : 01.04.2020

\title{
İhracat Pazar Yönelimi Boyutlarının İhracat Performansı Üzerindeki Etkisi: Bir Meta-Analiz Çalışması
}

\author{
Nilay Bıçakcıoğlu-Peynirci ${ }^{1}$ \\ Ilayda İpek²
}

İhracat Pazar Yönelimi Boyutlarının İhracat Performansı Üzerindeki Etkisi: Bir Meta-Analiz Çalışması

Öz

Bu çalışma, ilgili literatürde ihracat pazar yönelimi boyutları ve ihracat performansı arasındaki ilişkiyi incelemiş olan ampirik bulguları sentezlemeyi ve bu ilişki üzerinde etkisi olabileceği düşünülen bağlamsal ve ölçümsel moderatör değişkenleri ortaya çıkarmayı hedeflemektedir. Bu meta-analiz çalışması 70 etki büyüklüğünü $(N=2,829)$ inceleyerek, ihracat pazar bilgisi oluşturmanın, diğer ihracat pazar yönelimi boyutlarına kıyasla, ihracat performans göstergelerini iyileştirmede daha etkili olduğunu ve öznel ve ekonomik olmayan ölçümsel moderatörlerin ise ihracat pazar yönelimi yüksek firmaların performansını geliştirmede daha önemli bir rol oynadığını ortaya koymaktadır. Bunun yanı sıra, ihracat pazar yönelimi ile ihracat performansı arasındaki ilişkinin büyüklüğü hem ekonomisi gelişmiş hem de gelişmekte olan ülkeler için benzer bir durum sergilemekte ve ihracat pazar yöneliminin ihracat pazarlarında başarıyı yakalamasına yardımcı olduğu görülmektedir.

Anahtar Kelimeler: İhracat Pazar Yönelimi, İhracat Performansı, Meta-Analiz, Ölçümsel Faktörler, Bağlamsal Faktörler
The Influence of the Dimensions of Export Market Orientation on Export Performance: A Meta-Analysis Study

Abstract

This study aims to quantitatively synthesize all empirical research on the link between the dimensions of export market orientation and export performance, and to investigate the effects of possible contextual and measurement moderators on these relationships. This meta-analysis examining 70 total effects $(N=2,829)$ demonstrates that export market intelligence generation has a more powerful effect on export performance in comparison with other dimensions of export market orientation. Moreover, the meta-analytic evidence also indicates that the association between export market orientation and export performance is stronger for the studies measuring the performance construct with subjective items and concentrating on its non-economic indicators. Also, the magnitude of the correlation between export market orientation and export performance reveals identical results for both developed and developing economies in achieving better export performance.

Keywords: Export Market Orientation, Export Performance, Meta-Analysis, Measurement Factors, Contextual Factors

\section{Giriş}

Günümüz iş dünyasında neredeyse bütün pazarların devingen bir yapıya sahip olduğu ve bu yüzden firmaların sundukları ürün/hizmetleri sürekli iyileştirmesi gerektiği yadsınamaz bir gerçektir (Hurley ve Hunt, 1998). Buna bağlı olarak, müşterilerin devamlı değişen ihtiyaç ve tercihlerine ve rakiplerin stratejik hareketlerine uygun bir biçimde karşlık verebilmek için, firmalar pazara dayalı en güncel bilgiyi takip etmek; bir başka ifadeyle, pazar yönelimli olmak durumundadır (Jaworski ve Kohli, 1993). Pazar yönelimi pazarı öğrenmekle yakından ilişkilidir (Özsomer ve Gençtürk, 2003); öyle ki, pazar yönelimli firmalar dış paydaşlar hakkında düzenli bir şekilde bilgi toplar ve bu toplanılan bilgiyi yüksek müşteri değerli ürün/hizmetlere dönüştürür (Slater ve Narver, 1995). Ancak, önemli bir nokta olarak, bir firmanın yerel çevrede pazar yönelimli

\footnotetext{
${ }^{1}$ Arş. Gör. Dr., Dokuz Eylül Üniversitesi İşletme Fakültesi, Uluslararası İşletmecilik ve Ticaret Bölümü. nilay.bicakcioglu@deu.edu.tr, Yazar ORCID bilgisi: https://orcid.org/0000-0002-7705-3827.

${ }^{2}$ Arş. Gör. Dr., Dokuz Eylül Üniversitesi İşletme Fakültesi, İşletme Bölümü. ilayda.gungor@deu.edu.tr, Yazar ORCID bilgisi: https://orcid.org/0000-0001-7095-4078.
} 
olması bu firmanın ihracat pazarlarında da aynı davranışı göstereceği anlamına gelmemektedir (Cadogan vd., 2001).

Pazar yönelimli olmak pazar bilgisini toplamaya, paylaşmaya ve yorumlamaya yüksek ilgilenim duyulmasını gerektirdiği için, ihracat pazarlarındaki bilgi kanalları yerel pazarlara göre daha az gelişmiştir ve bu sebeple bir firmanın yerel çevredeki pazar yönelimiyle aynı firmanın ihracat bağlamındaki pazar yönelimli stratejisi birbirine benzememektedir (Cadogan vd., 2002). Bu doğrultuda, yerel pazarlar yerine ihracat pazarları üzerinde durması ile (Cadogan vd., 2003), ihracattaki pazar yönelimi genel anlamda bir firmanın pazarlama kavramını ihracat alanı ile ilişkilendirmesini ifade etmektedir (Cadogan vd., 2009). Hedef pazarlar hakkında en son bilgiyi toplama, tüketici taleplerinin detaylarını anlama ve dış pazarlardaki rakipler arasında başarılı bir şekilde öne çıkaracak stratejiyi geliştirme fırsatı sunduğu için, pazar yönelimi yetkinliği özellikle ihracat firmaları için büyük önem arz etmektedir (He vd., 2013). İhracat pazarı yönelimli firmalar sürekli ve düzenli pazar araştırması yapmaktadır ve böylece ihracat pazarlarındaki değişimlere hızlı bir biçimde yanıt verebilmektedir (Murray vd., 2011).

İlgili literatürde pazar yöneliminin kavramsallaştırılmasında iki farklı yaklaşımın (davranışsal ve kültürel yaklaşım) öne çıktığı görülmektedir (Homburg ve Pflesser, 2000). Bunlardan davranışsal yaklaşım pazar yönelimini pazar bilgisinin üretimine ve yayılımına odaklanan örgütsel bir etkinlik olarak tanımlarken (Örn: Kohli ve Jaworski, 1990), kültürel yaklaşım ise pazar yöneliminin müşteri değeri yaratma sürecini hızlandıran norm ve inançları kapsayan örgütsel kültürün bir parçası olduğunu savunmaktadır (Örn: Deshpandé vd., 1993; Narver ve Slater, 1990). Farklı ilkelere dayanmalarına karşın, her iki yaklaşım da müşterinin pazar yöneliminin en önemli parçası olduğu üzerinde yoğunlaşmaktadır (Mavondo ve Farrell, 2000). Daha detaylı olarak, davranışsal yaklaşıma göre, firmaların ihracat alanında yaptığı pazar yönelimli stratejiler "ihracat pazar yönelimi" olarak adlandırılmaktadır ve "ihracat pazar bilgisi oluşturma", "ihracat pazar bilgisinin yayılımı" ve "ihracat pazarına cevap verilebilirlik", bu kavramın boyutlarını oluşturmaktadır (Cadogan vd., 1999; Cadogan vd., 2009).

Var olan literatürde ihracat pazar yönelimi genellikle boyutlar birleştirilerek incelenmiş olsa da ihracat pazar yönelimi çıktılarını anlamada daha iyi sonuçlar ortaya koyacağından ihracat pazar bilgisi oluşturma, ihracat pazar bilgisinin yayılımı ve ihracat pazarına cevap verilebilirlik boyutlarının ayrı ayrı sınanmasının da gerektiği ileri sürülmektedir (Chung, 2012; Sørensen, 2009). Özellikle, ihracat performansı açısından her bir boyutun farklı bir etki yarattığı yapılan ampirik çalışmalarla kanıtlanmıştır (Örn: Akyol ve Akehurst, 2003; Chung, 2012; Rose ve Shoham, 2002). Ancak, yapılan çalışmalarda raporlanan sonuçlar değişkendir. Örneğin, ihracat pazarına cevap verilebilirlik ile ihracat performansı arasında anlamlı ve olumlu bir ilişki olduğu çoğunlukla ortaya konulurken, ihracat pazar bilgisi oluşturma ve ihracat pazar bilgisinin yayılımının ihracat performansı üzerindeki etkisi açısından bulgular farklılık göstermektedir (Örn: Murray vd., 2007; Rose ve Shoham, 2002).

Daha önce pazar yönelimi üzerine olan ampirik çalışmaları birleştirmek adına yapılan ve faydalı iç görüler sunan meta-analitik araştırma girişimleri olmuştur; fakat, bu çalışmaların kapsamı yerel bağlam ile sınırlıdır. Yerel bağlamdaki meta-analitik araştırmalar daha çok pazar yönelimiperformans ilişkisi üzerine yoğunlaşırken (Örn: Cano vd., 2004; Ellis, 2006; Kirca vd., 2005; Shoham vd., 2005; Shoham vd., 2006), birkaç meta-analizi ise daha özgül konulara değinerek pazar yöneliminin inovasyon sonuçlarını (Örn: Chang vd., 2014; Grinstein, 2008a) ya da stratejik yönlülük çıktılarını (Örn: Grinstein, 2008b) incelemiştir. Buradan yola çıkarak, ihracat alanındaki 
pazar yönelimi literatürüne ait ampirik bulguların bütünleştirilmesi ve bu literatürün ihracat pazar yönelimi boyutlarında ayrı ayrı ele alınması ihtiyacı doğmaktadır.

Uluslararası pazarlama literatüründeki bu araştırma eksikliğini gidermek için, bu çalışma meta-analitik yaklaşımı benimseyerek ihracat pazar yönelimi boyutları ve ihracat performansı arasındaki ilişkiyi sayısal bir şekilde sentezlemeyi hedeflemektedir. Ayrıntılı olarak, çalışmanın amaçları üç bölümden oluşmaktadır: (1) ihracat pazar bilgisi oluşturma, ihracat pazar bilgisinin yayılımı ve ihracat pazarına cevap verilebilirlik boyutlarının ihracat performansı üzerindeki etkisini inceleyen önceki ampirik araştırmaların meta-analizini yapmak, ve ihracat pazar yönelimi boyutları ve ihracat performansı arasındaki korelasyon değerlerini raporlamak; (2) öznel/nesnel ve ekonomik/ekonomik olmayan ölçüm birimlerinin ve ülkelerin ekonomik gelişmişlik düzeyinin ihracat pazar yönelimi boyutları ve ihracat performansı arasındaki ilişki üzerindeki moderatör rolünü sınamak; ve (3) ihracat pazar yönelimi literatürünü geliştirmek adına teorik ve yönetimsel öneriler sunmaktır.

\section{Kavramsal Çerçeve}

Şekil 1.'de meta-analizine ait kavramsal çerçeve gösterilmektedir. Bu kavramsal çerçeveye ve ilgili literatüre dayalı olarak çalışmanın hipotezleri (H1-H6) geliştirilmiştir.

Şekil 1. Kavramsal çerçeve

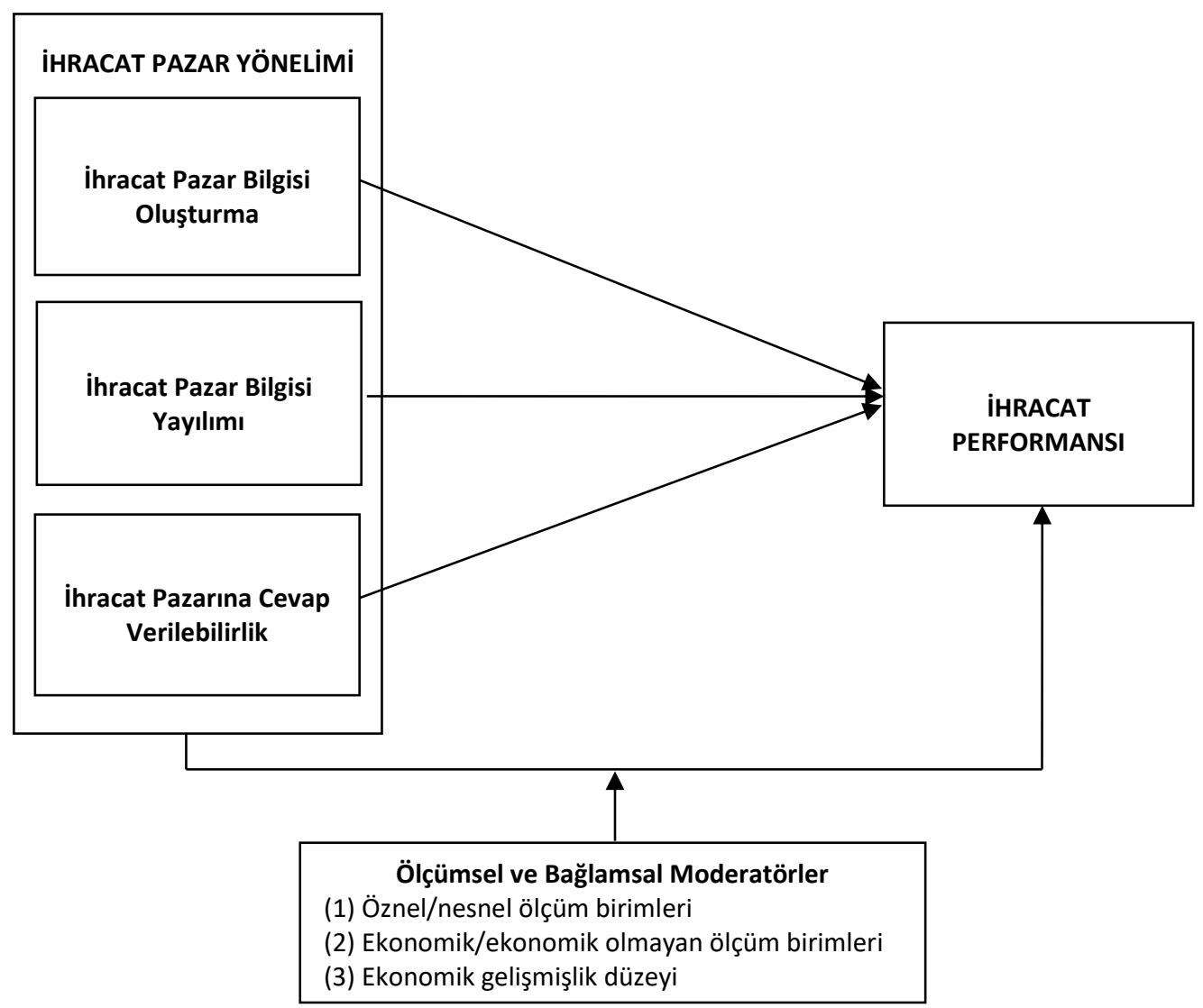




\subsection{Ihracat Pazar Yönelimi ve Ihracat Performansı}

\subsubsection{Ihracat Pazar Bilgisi Oluşturma ve İhracat Performansı}

Ihracat pazar bilgisi oluşturma genel olarak bir firmanın ihracat müşterilerinin şimdiki ve gelecekteki ihtiyaç ve istekleri, firmanın ihracat pazarlarındaki rekabet durumu ve diğer çevresel etkenler hakkında (Örn: teknolojik ve düzenleyici değişimler) bilgi toplaması olarak tanımlanmaktadır (Cadogan vd., 2003; Kohli vd., 1993). İhracat firmalarının uluslararası pazarlar ile ilgili daha çok bilgi elde etmesi ve uluslararası pazarlara karşı daha olumlu algılar geliştirmesi bu firmaların ihracat operasyonlarına daha çok kaynak ayırmaya ve daha sistematik bilgi işleme süreçlerini kullanmaya istekli olmalarına sebep olmaktadır (Yeoh, 2000). Bununla birlikte, ihracat firmaları uluslararası pazarlardaki tehdit ve fırsatları daha başarılı bir şekilde tespit ederek uygun stratejileri geliştirebilmektedir (Rose ve Shoham, 2002). Ayrıca, dış çevrenin iyi çözümlenmesi ihracat firmalarının rakiplerine göre uluslararası pazarlarda daha iyi konumlanmalarına ve daha iyi performans göstermelerine olanak sağlamaktadır (Cadogan vd., 2002). İlgili literatürde ihracat pazar bilgisi oluşturmanın ihracat performansını arttırmadaki etkisi önemle vurgulanmaktadır (Örn: Murray vd., 2007; Rose ve Shoham, 2002; Yeoh, 2000). Buna göre,

$\mathbf{H}_{1}$ : ihracat pazar bilgisi oluşturmanın ihracat performansı üzerinde olumlu bir etkisi vardır.

\subsection{2. İhracat Pazar Bilgisinin Yayılımı ve İhracat Performansı}

Ihracat pazar bilgisinin yayılımı resmi ve resmi olmayan etkinlikler yoluyla ihracat pazar bilgisinin ihracat personelleri arasında, ihracat personelleri ile diğer departmanlar arasında (Örn: pazarlama veya araştırma ve geliştirme) veya firmanın tamamında paylaşımını nitelendirmektedir (Cadogan vd., 2001; Murray vd., 2007). İhracat pazar bilgisi ilgili yöneticilerle zamanında paylaşıldığı takdirde değerlidir ve bilgi paylaşımı örgütsel öğrenme yoluyla yeni bilginin veya anlayışın oluşumuna katkıda bulunur (Huber, 1991; Sørensen, 2009). Bunun dışında, ihracat pazarlarındaki müşterilere, rakiplere ve çevresel koşullara etkili bir şekilde karşılık verebilmek firma bünyesindeki bütün departmanların etkin katılımını gerektirir ve bu noktada ihracat pazar bilgisinin ilgili departmanlar ve bireyler arasında doğru iletimi ve yayılımı büyük önem taşımaktadır (Kohli ve Jaworski, 1990; Narver ve Slater, 1990). Firmaya, firmanın müşterilerine ve rakiplerine etki edecek ihracat pazar bilgisinin firma bünyesinde etkili bir şekilde yayılımının ihracat başarısını arttırmada önemli bir rol oynadığı şiddetle savunulmaktadır (Örn: Akyol ve Akehurst, 2003; Hart ve Tzokas, 1999; Yeoh, 2000). Bu doğrultuda,

$\mathbf{H}_{2}$ : ihracat pazar bilgisinin yayılımının ihracat performansı üzerinde olumlu bir etkisi vardır.

\subsubsection{Ihracat Pazarına Cevap Verilebilirlik ve İhracat Performansı}

ihracat pazarına cevap verilebilirlik ise bir firmanın hem iç hem de dış çevresinde olan değişimlere (Örn: ürün standardizasyon düzeyi, dış fiyat politikaları, ihracat müşteri hizmeti) ihracat pazar bilgisini kullanarak nasıl ve ne şekilde karşılık verileceği ile ilgili planlardır (Cadogan vd., 2001; Jaworski ve Kohli, 1993). Bir firma ihracat pazar bilgisini firma içinde oluşturabilir ve yayabilir; ancak bu firmanın pazardaki ihtiyaçlara cevap verememesi durumunda büyük bir başarının elde edildiğini söylemek mümkün değildir (Kohli ve Jaworski, 1990). Buna bağlı olarak, bir firmanın stratejik hedeflerini gerçekleştirebilmesi için ihracat müşterilerine, rakiplere veya uluslararası operasyonları etkileyecek çevresel değişikliklere yüksek düzeyde karşılık verebilmesi gerekmektedir (Chung, 2012). Özellikle, bir firmanın düzenli bir biçimde müşterilerinin şimdiki ih- 
tiyaç ve tercihlerine cevap vermesi ve gelecek dönemdeki ihtiyaç ve tercihlerini tahmin edebilmesi ve rakiplerinin stratejik hareketlerini iyi tahlil edebilmesi durumunda müşterileri tatmin etmede rakiplerinden daha iyi bir konumda olacağı ve yüksek müşteri değeri yaratacağı vurgulanmaktadır (Cadogan vd., 2002; Narver ve Slater, 1990). Ayrıca, ilgili literatürde ihracat pazarına cevap verilebilirlik ile ihracat performansı arasında olumlu ve anlamlı bir ilişki bulunduğu ortaya konulmaktadır (Örn: Chung, 2012; Murray vd., 2007; Rose ve Shoham, 2002). Buradan yola çıkarak,

$\mathbf{H}_{3}$ : Ihracat pazarına cevap verilebilirliğin ihracat performansı üzerinde olumlu bir etkisi vardır.

\section{2. İhracat Pazar Yönelimi ve İhracat Performansı Arasındaki İlişkiyi Etkileyen Ölçümsel ve Bağlamsal Moderatörler}

Ihracat pazar yönelimi ve ihracat performansı arasındaki ilişkiye odaklanan önceki ampirik çalışmalar literatürde birbirinden çeşitli ve tutarsız bulgular ortaya koymaktadır. Örneğin, çalışmaların önemli bir kısmı ihracat pazar yöneliminin ihracat performansı üzerindeki istatistiksel olarak anlamlı bir etkisi olduğunu açığa çıkarırken (Örn: Cadogan vd., 2012; Chang ve Fang, 2015), bazı çalışmalarda ise bu değişkenler arasındaki ilişkiyi desteklememektir (Örn: Acosta vd., 2018; Navarro-Garcia vd., 2014). Literatürde yer alan bulgular arasındaki bu farklılıklar, bu ilişki üzerinde etkisi olabilecek bir takım moderatör değişkenlerinde varlığını ortaya çıkarmaktadır (Greenley, 1995; Han vd., 1998; Kumar vd., 1998; Slater ve Narver, 1994). Buradan yola çıkarak, bu meta-analiz çalışmasında, ihracat pazar yönelimi ve ihracat performansı arasındaki ilişki üzerinde önemli bir etkiye sahip olması beklenen (Örn: Cano vd., 2004; Ellis, 2006), ölçümsel (ekonomik/ekonomik olmayan ölçüm birimleri, öznel/nesnel ölçüm birimleri) ve bağlamsal moderatörleri (ülkelerin ekonomik gelişmişlik düzeyi) ve incelenmektedir.

\subsection{1. Öznel/Nesnel Ölçüm Birimleri}

Literatürde pazar yönelimi ve performans arasındaki ilişkiyi inceleyen çalışmalara bakıldığında, çalışmaların büyük çoğunluğunda, nesnel ölçüm öğelerine nazaran, daha çok öznel ölçekler yardımıyla performansın ölçüldüğü gözlenmektedir (Örn: Diamantopoulos ve Hart, 1993; Doyle ve Wong, 1998; Kayabasi ve Mtetwa, 2016). Bilindiği üzere, performans literatürde yaygın olarak, (a) firma performansı ile ilgili soruların katıcılımcıların öznel ölçekler yardımıyla yönetici algılarına dayanarak sorulması (Örn: Covin vd., 1990; Golden, 1992; Govindarajan, 1988); (b) firma performansı ile ilgili rakamsal bilgilerin ikincil verilere dayandırılarak yöneticilere nesnel olarak sorulması (Örn: Chakravarthy, 1986; Cronin ve Page, 1988; Venkatraman ve Ramanujam, 1986) olmak üzere iki şekilde işlemleştirilmektedir. Literatürde öznel ölçekler aracılığıyla performans değişkenini değerlendiren çalışmalar, çalışmalarını öznel yanıtlar ile nesnel ölçüm işlemlerinden yararlananlar arasında daha önceki araştırmalarda ortaya çıkarılan güçlü bir korelasyon olması temeline dayandırmaktadırlar (Dess ve Robinson, 1984; Robinson ve Pearce, 1988; Venkatraman ve Ramanujam, 1986). Ayrıca, Harris (2001)'in de araştırmasında belirttiği üzere, pazar yöneliminin firma performansı üzerine etkisi, araştırmacıların kullanmış oldukları performans ölçüm şeklinin öznel ya da nesnel olmasına göre değişiklik göstermektedir. Buna ek olarak, öznel ölçümler kullanılması halinde, ortak yöntem varyansının, pazar yönelimi ve performans arasındaki ilişkinin gücünü kuvvetlendirmesi beklenmektedir (Doty ve Glick, 1998). Buna göre, 
$\mathbf{H}_{4}$ : İhracat pazar yönelimi ve ihracat performansı arasındaki ilişki, ihracat performansının nesnel ya da karma ölçüm birimleri yerine, öznel ölçüm birimleriyle değerlendirilmesi durumunda daha güçlüdür.

\subsubsection{Ekonomik/Ekonomik Olmayan Ölçüm Birimleri}

ihracat performansı literatürde birçok araştırmacı tarafından çok boyutlu bir yapı olarak ele alınmakta ve hem ekonomik hem de ekonomik olmayan alt bileşenler yardımıyla ölçülmektedir (Katsikeas vd., 2000). Örneğin, literatürde önceki çalışmaların bir kısmı firmaların ihracat performansını, ihracat pazarlarında elde etmiş oldukları ekonomik başarıların derecesine bağlı olmasına dayandırarak, ihracat performansını 'ihracat pazarlarındaki satış etkinliği', 'ihracat karı', 'ihracat satışları', 'ihracat satışlarının son üç yıldaki büyüme oranı' ve 'yıllık ihracat rakamlarının sektör ortalamasına oranla büyüme hızı' gibi finansal ölçütler ile değerlendirmekte iken (Örn: Cadogan vd., 2003; Boso vd., 2018), bazı araştırmacılar ise firmanın ihracat pazarlarındaki performansını, 'pazar payı', 'pazara giriş stratejisi', 'yeni ürün başarısı', 'pazardaki müşteri memnuniyeti/sadakati', 'rakiplere oranla başarısı', 'stratejik büyüme oranı' ve 'memnuniyet ve beklentilerini karşılama düzeyleri' gibi daha strateji ve pazar odaklı performans ölçütleri ile değerlendirdikleri görülmektedir (Örn: Chung, 2012; Lengler vd., 2016; Lin vd., 2014).

Bu bağlamda, ihracat pazar yöneliminin ihracat performansı üzerinde çok önemli etkilere sahip olduğu ihracat performansı hem ekonomik hem de ekonomik olmayan ölçüm birimleri ile ölçüldüğünde fark edilmekte ve birçok araştırmacı tarafından ihracat pazar yöneliminin hem pazar ve stratejik odaklı performans hem de finansal performans üzerinde etkisi olduğu doğrulanmaktadır (Örn: Cadogan vd., 2003; Homburg ve Pflesser, 2000). Bununla birlikte, kaynak temelli yaklaşıma dayanarak, ihracat pazar yönelimi yüksek olan firmalar, uluslararası pazarlarda onlara rekabet avantajı kazandıracak daha etkili stratejik kararlar alabilmesi (Ketchen vd., 2007) ve ihracat pazar yöneliminin pazar odaklı stratejik esneklik ve çözümler sağlaması açısından (Javalgi vd., 2005), ihracat pazar yönelimi ile ihracat performansı arasındaki ilişkinin ihracat performansı ekonomik olmayan ölçüm birimleriyle değerlendirildiğinde daha etkili olacağı beklenmektedir. Buradan yola çıkarak,

$\mathbf{H}_{5}$ : ihracat pazar yönelimi ve ihracat performansı arasındaki ilişki, ihracat performansının ekonomik ölçüm birimleri yerine, ekonomik olmayan ölçüm birimleriyle değerlendirilmesi durumunda daha güçlüdür.

\subsubsection{Ekonomik Gelişmişlik Düzeyi}

ihracat pazarlaması literatüründeki gelişmiş ülke bağlamında yapılan çalışmaların birçoğunda ihracat pazar yönelimi ve ihracat performansı arasında pozitif yönde bir ilişki olduğu ortaya konulmaktadır (Örn: Cadogan vd., 2002; Chung, 2012; Pascucci vd., 2016). Çok sayıda ampirik kanıtın bu doğrultuda olmasının sebebi gelişmekte olan ülkelere kıyasla, gelişmiş ekonomilerin sürekli değişmekte olan pazar ve teknolojik çevreler ile çevrili olmasına bağlanabilir (Hooley vd., 2000) ve bu durum da çevresel belirsizliklerle baş edebilmek için pazarı anlamaya daha çok odaklanmayı gerektirmektedir (Cadogan vd., 2002; Cadogan vd., 2012). Buna bağlı olarak, ihracat pazar yönelimi açısından, gelişmekte olan ve gelişmiş ekonomiler arasında önemli farklılıkların olduğu varsayılmakta (Murray vd., 2007) ve gelişmiş ülkelerde ihracat pazar yönelimli olmanın daha fazla kazanç ve getiri sağlamasının daha olası olduğu savunulmaktadır (Ellis, 2005; Ellis, 2006). Bu doğrultuda, 
$\mathbf{H}_{6}$ : Ihracat pazar yönelimi ve ihracat performansı arasındaki ilişki, ülkelerin ekonomik gelişmişlik düzeyine göre değerlendirilmesi durumunda, gelişmiş ülkelerde daha güçlüdür.

\section{Araştırmanın Yöntemi}

\subsection{Veritabanı Oluşturulması}

Araştırmaya dahil edilme ölçütlerinin doğru olarak belirlenmesinin meta-analizi bulguları üzerindeki önemli etkisi göz önünde bulundurularak (Grewal vd., 2018; Hunter ve Schmidt, 2004), ihracat pazar yönelimi ve ihracat performansı ilişkisi üzerine olan seçkin çalışmaları belirlemek için dört ölçüt tanımlanmıştır. Bu ölçütlere göre, meta-analitik araştırmaya dahil edilebilmesi için ilgili çalışmada: (a) ihracat pazar yönelimi ve ihracat performansı arasındaki ilişkinin araştırılması, (b) ihracat pazar yöneliminin ihracat pazar bilgisi oluşturma, ihracat pazar bilgisinin yayılımı ve ihracat pazarına cevap verilebilirlik boyutları ile ölçülmüş olması, (c) ihracat performansının öznel ve/veya nesnel ölçme birimleri ile değerlendirilmiş olması, ve ilgili çalışmanın (d) birincil veya ikincil veri kullanarak ampirik bir araştırma olması ve Pearson korelasyon katsayısı veya türevlerini raporlaması gerekmektedir (Cooper vd., 2009).

Belirlenen ölçütler doğrultusunda ilgili çalışmaları bulmak için hem elektronik hem de manuel arama yöntemlerinden yararlanılmıştır. Elektronik arama yöntemi, elektronik veritabanlarının (Örn: EBSCO, Elsevier ve JSTOR) "market orient*”, "pazar yönlülük”, "pazar yönelimi” ve "pazar oryantasyonu" anahtar kelimelerinin, "export performance" ve "ihracat performansı" anahtar kelimeleri ile birlikte taranması ile gerçekleştirilmiştir. Manuel arama yönteminde ise, elektronik veritabanları yoluyla bulunan ilgili makalelerin kaynaklar bölümleri gözden geçirilerek ilgili literatürde göz ardı edilen bir çalışma olmadığından emin olunmak istenmiştir. İzlenen arama yöntemleri sonucunda, ihracat pazar yönelimi ve ihracat performansı ilişkisini inceleyen 38 çalışma elde edilmiş; ancak bu çalışmalardan 28 tanesi araştırmaya dahil edilme ölçütlerini karşılamadıkları gerekçesi ile veritabanından çıkarılmıştır. Bir çalışmanın kavramsal olarak eşit; ama istatistiksel olarak farklı bölümler ile gruplandırılabilmesi durumunda her bir bulgunun bağımsız bir şekilde analize dahil edilebileceği görüşüne dayalı olarak (Grewal vd., 2018), bu metaanalitik araştırmada 2,829 sayıda firmanın oluşturduğu örneklemden elde edilen 70 adet etki büyüklüğü hesaplanmıştır.

Bu bağlamda, 2000 ve 2018 yılları arasında yayınlanan ilgili makaleler meta-analizi için kodlanmıştır. Kodlama hatalarının önüne geçmek adına (Lipsey ve Wilson, 2001), veri iki farklı kodlayıcı tarafından önceden belirlenen ve ana hatları ile üç bölümden oluşan bir kodlama şeması ile uyumlu olarak kayıt altına alınmıştır. Kodlama şemasının ilk bölümünde araştırmaya dahil edilen çalışmalara ait başlıca özellikler (Örn: çalışmanın; ismi, yayınlandığı derginin ismi, odaklandığı endüstri; yapıldığı ülke, içerdiği firmaların büyüklüğü) kodlanmıştır. İkinci bölümünde, ilgili çalışmaların yöntemsel özellikleri (Örn: örneklem sayısı, veri toplama yöntemi, veri analizi teknikleri, ihracat pazar yönelimi ve ihracat performansı değişkenleri için güvenilirlik değerleri ve kullanılan ölçekler, ulaşılabilen etki büyüklüğü değerleri) incelenmiştir. Son bölümde ise, moderatör değişkenlerinin etkisini incelemek için, araştırmaya dahil edilen makalelerdeki ihracat performansı ölçekleri öznel/nesnel/karma ve ekonomik/ekonomik olmayan ölçüm birimlerine göre ve ülkelerin ekonomik gelişmişlik düzeyi Birleşmiş Milletler'in (2018) önermiş olduğu sınıflandırmaya (gelişmekte olan ve gelişmiş ülkeler) bağlı kalınarak kodlanmıştır. Anlaşmazlıkların karşılıklı görüşmeler sonucunda giderilmesiyle birlikte kodlayıcılar arası güvenilirlik \%90 ile \%95 düzeyinde değişmiştir (Szymanski ve Henard, 2001). 


\subsection{Meta-Analiz Süreci}

Meta-analiz şu ana kadar o alanda yapılmış olan çalışma sonuçlarını birleştiren ve nicel olarak sentezleyen bir yöntem olarak karşımıza çıkmaktadır (Glass, 1976; Geykens vd., 2009). Ayrıca, meta-analiz ihracat pazar yöneliminin boyutları ile ihracat performansı arasındaki ilişkinin gücünü, literatürde yapılmış olan önceki çalışmaların bulgularına dayanarak, sistematik bir şekilde sayısallaştırarak ve birleştirerek ortalama bir etki değeri ortaya çıkarmakta ve bu ilişkiyi önemli düzeyde etkilemekte olan olası moderatör ve bağlamsal değişkenleri de ortaya koymaktadır (Hunter ve Schmidt, 2004). Bu çalışmada, ihracat pazar yöneliminin boyutları ve ihracat performansını inceleyen birbirinden bağımsız çalışmalarda yer alan korelasyon katsayıları metaanaliz yöntemi kullanılarak analiz edilmiştir. Pazarlama literatüründe daha önce yapılmış olan birçok meta-analiz çalışması ile tutarlı olarak (Örn: Geyskens vd., 1998; Henard ve Szymanski, 2001; Janiszewski vd., 2003; Kirca vd., 2005; Palmatier vd., 2006), korelasyon katsayıları ya da korelasyon katsayılarına dönüştürülebilen istatistiki değerler bu meta-analiz çalışmasında etki büyüklüğü olarak dikkate alınmıştır. Buna ek olarak, bir çalışmada birden fazla etki büyüklüğü olması durumunda, korelasyon katsayılarının ortalaması alınarak analize dahil edilmiştir (Borenstein vd., 2009).

Bunun yanı sıra, hata ölçümlerine ilişkin olarak, birbirinden bağımsız etki büyüklüklerinin güvenirlik katsayısının kareköküne bölünmesi sonucunda elde edilen düzeltilmiş korelasyon katsayı değerleri analizlerin devamı için hesaplanmıştır (Hunter ve Schmidt, 2004). Bununla birlikte, güvenirlik katsayı değerleri belirtilmemiş değişkenler için, var olan tüm güvenirlik katsayı değerlerinin ortalaması değerlendirilmeye alınmıştır (Örn: Ellis, 2006; Kirca vd., 2005). Güvenirlik katsayı değeri ortalaması, Cadogan vd. (1999)'nin ihracat pazar yönelimi ölçeği için, 0,909 olarak hesaplanmıştır. Daha sonrasında, düzeltilmiş korelasyon katsayıları, önce Fisher z değerlerine dönüştürülmüş, ancak sonrasında meta-analiz bulguları rapor edilirken, değerler tekrar korelasyon katsayısına dönüştürülmüştür (Borenstein vd., 2009). Bu çalışmada, meta-analiz yöntemi olarak, Hunter ve Schmidt (2004)'in önermiş olduğu yönergeler takip edilmiştir. Illk olarak, meta-analiz bulgularının sağlamlığını test etmek için sıklıkla kullanılan üç ayrı istatistiksel yönteme başvurarak, yayın yanlılığına bakılmıştır (Geykens vd., 2009; Grewal vd., 2018). Bu doğrultuda, çalışmanın bulgularını istatistiksel olarak anlamsız çıkması için gerekli olan çalışma sayısını tanımlamak için, Rosenthal (1979)'in 'dosya çekmecesi (file-drawer)' yönteminden yararlanılmış ve $\mathrm{N}$ sayısı $(30,935)$, dosya çekmecesi probleminin bu çalışma için bir sorun teşkil etmediğini göstermiştir. İkinci olarak, bir meta-analizde eksik olabilecek çalışma sayısını hesaplamaya yardımcı Orwin'in 'güvenli N (fail-safe N)' (0.05'e sabitlenen) sayısı da, yayın yanlılığının bu çalışmada çok düşük olasılıkta ortaya çıkabileceğini göstermiştir (Orwin, 1983). Son olarak, Duval ve Tweedie (2000)'nin 'çıkar ve ekle (trim and fill)' yöntemi ile huni grafiğinin pozitif tarafında yer alan küçük çalışmaların çıkarılıp eklenmesi ile yeniden hesaplanan etki büyüklüğü ile grafiğin daha simetrik bir görünüme sahip olup olmayacağına bakılmıştır. Bu grafik de, yayın yanlılığının bu meta-analiz çalışmasında bir problem teşkil etmeyeceğini doğrulamıştır.

Buna ek olarak, duyarlılık analizi, orman grafiğinin yorumlanması sonucundan yararlanılarak yürütülmüş olup, belirsizliği azaltma amaçlı bu çalışmada kullanılmıştır. Duyarlılık analizi sonuçlarına göre, düşük kaliteli çalışmalar analizden çıkarıldığında, heterojenlik istatistiksel olarak anlamlı bir şekilde var olduğundan, bu gözlenen heterojenliğin çalışmaların kalitesi ile ilgili olmadığı sonucuna varılabileceğini göstermiş olduğundan, gözlenen aykırı değerler çalışmadan çıkarılmamıştır (Borenstein vd., 2009). Analizler esnasında uygun modelin seçilebilmesi açısından, 
heterojenlik testi yapılmış olup, ortaya çıkan bulgular meta-analiz çalışmasında yer alan çalışmaların varyanslarının istatistiksel olarak anlamlı olarak ve heterojen bir şekilde dağılım gösterdiğini ortaya koymaktadır (Q-değeri $(69 \mathrm{sd})=581,047(p=0.000), 12=88,125)$ (Cooper vd., 2009). Bu doğrultuda, farklı çalışmalarda farklı etki büyüklerinin olduğu varsayımına dayanarak, analizler 'rastgele etki modeli' kullanılarak yapılmıştır (Borenstein vd., 2009; Grewal vd., 2018). Ayrıca, istatistiksel olarak anlamlı bulunan heterojenlik testi, bu meta-analiz çalışmasında var olabilecek olası moderatörlerin varlığına da işaret etmektedir (Geyskens vd., 2009; Hunter ve Schmidt, 2004). Buna benzer olarak, anlamlılık düzeyi \%95 olan ve sıfır içermeyen bir güven aralığı da etki büyüklükleri arasında heterojenlik olduğunu ve ilgili değişkenler arasında istatistiksel anlamlı bir ilişki olduğunu doğrulamaktadır (Finkelstein vd., 1995).

\section{Araştırmanın Bulguları ve Tartışma}

Bu meta-analitik çalışmada ihracat pazar yönelimi boyutlarının ihracat performansı üzerindeki etkisi ile ilgili önerilen hipotezler Comprehensive Meta-Analysis (CMA versiyon 2.2.057) yazılımı ile sınanmıştır. Tablo 1.'de teorik yapılar arasındaki doğrudan ilişkileri ve moderatör analizini gösteren meta-analitik bulgular sunulmaktadır. $\mathrm{H}_{1}$ ile uyumlu olarak, ihracat pazar bilgisi oluşturmanın ihracat performansı üzerinde olumlu bir etki yarattığı doğrulanmıştır ( $r=$ 0,252; GA95\%: 0,202-0,301). Bu sonuç ihracat pazarlarındaki paydaşlar hakkında tam ve doğru bilgi edinmenin ihracat başarısını arttıracağını savunan ve bunu ampirik bulgularla ortaya koyan çalışmalar ile aynı doğrultudadır (Örn: Murray vd., 2007; Rose ve Shoham, 2002; Yeoh, 2000).

Ayrıca, meta-analitik sonuçlar ihracat pazar bilgisi yayılımı ile ihracat performansı arasında olumlu ve istatistiksel olarak anlamlı bir ilişki olduğunu göstermektedir ( $r=0,185 ;$ GA95\%: 0,127 $-0,243)$. Bu bulgu ihracat pazar bilgisinin firma bünyesindeki birimler arasında paylaşılmasıyla pazar yöneliminin daha etkin bir hale getirilebileceği ve bu şekilde performans çıktılarının güçlendirilebileceği nosyonuna bağlanabilir (Örn: Akyol and Akehurst, 2003; Hart ve Tzokas, 1999; Yeoh, 2000). Buna dayalı olarak, $\mathrm{H}_{2}$ kabul edilmiştir. Ayrıca, $\mathrm{H}_{3}$ 'te önerildiği gibi, bu meta-analizi ihracat pazarına cevap verilebilirliğin yüksek ihracat performansı yaratmadaki önemli etkisini ortaya koymaktadır ( $r=0,244$; GA95\%: 0,195-0,292). Buna göre, firmaların ihracat pazarlarını iyi tahlil ederek müşterilerinin istek ve beklentilerine, rakiplerinin stratejik hareketlerine ve dış çevredeki değişimlere zamanında ve uygun karşılıkları vermeleri durumunda hedef pazarlarda rekabet avantajı sağlayarak üstün ihracat performansı çıktıları elde etmeleri kuvvetle muhtemeldir (Örn: Chung, 2012; Murray vd., 2007; Rose ve Shoham, 2002).

$\mathrm{H}_{4}$ ile tutarlı olarak, ihracat pazar yönelimi ile ihracat performansı arasındaki ilişkinin gücü, ihracat performansının öznel ölçüm birimleri ile ölçülmesi durumunda, nesnel ya da karma ölçüm birimlerine göre istatistiksel olarak anlamlı bir farklılık ortaya koymakta (Q-değeri $(2 \mathrm{sd})=$ $18,974(p=0.000)$ ) ve daha kuvvetli olmaktadır ( $r=0,261 ;$ GA95\%: 0,232 -0,290). Bu durumda, öznel ölçüm birimlerinin, ihracat pazar yönelimi ile ihracat performansı arasındaki ilişki üzerinde moderatör etkisi yaratmakta olduğu doğrulanmaktadır. Bu bağlamda, ihracat pazar yönelimi ile ihracat performansı arasındaki ilişkinin, ihracat performansının nesnel ya da öznel ölçüm birimleriyle değerlendirilmesine göre farklılık gösterdiği (Harris, 2001) ve aynı katılımcının, birden fazla değişken üzerine algılara dayanarak ölçülen soruları aynı anda yanıtlamasının da o değişkenler arasındaki korelasyon katsayısını ortak yöntem varyansının da etkisiyle yükselteceğinden söz etmek mümkündür (Chang vd., 2010).

ihracat performansının ekonomik ya da ekonomik olmayan ölçüm birimleriyle değerlendirilmesi durumunda, ihracat pazar yönelimi ile ihracat performansı arasındaki ilişki üzerinde istatistiksel olarak anlamlı farklılıklar olduğu sonucuna varılmış $(Q$-değeri $(1 \mathrm{sd})=4,759(p=$ 
0,029)) ve çalışmalarda ekonomik olmayan ölçüm birimleri kullanılmasının, ihracat pazar yönelimi ve ihracat performansı arasındaki ilişkinin gücünü daha da kuvvetlendirdiği sonucu elde edilerek ( $r=0,276$; GA95\%: 0,223 - 0,327), $\mathrm{H}_{5}$ kabul edilmiştir. Bu bulgu, bu konuda yapılan literatürdeki önceki çalışmaları da destekleyerek, ihracat pazar yöneliminin, ihracat performansı üzerindeki etkisini incelerken, performans değişkenini ekonomik ya da ekonomik olmayan bakış açısıyla değerlendirmenin önemli bir fark yarattığını ortaya koymaktadır (Örn: Cadogan vd., 2003; Homburg ve Pflesser, 2000). Bunun yanı sıra, bu sonuç ihracat pazar yönelimli olmanın, firmalara pazar odaklı stratejik esneklik kazandırması sayesinde, firmaların ihracat pazarlarında rekabet avantajı elde etmelerine ve dolayısıyla performanslarını arttırabilmelerine olanak sağladığını açığa çıkarmaktadır (Ketchen vd., 2007).

Tablo 1. Meta-Analitik Bulgular

\begin{tabular}{|c|c|c|c|c|c|c|c|c|}
\hline $\mathrm{H}_{1-6}$ & illişki & $\begin{array}{c}\text { Etki } \\
\text { büyüklüğü } \\
\text { sayısı }\end{array}$ & $N$ & $\begin{array}{c}\text { Düzeltilmiş } \\
r\end{array}$ & $\begin{array}{l}\text { Std. } \\
\text { hata }\end{array}$ & $\begin{array}{c}-95 \% \\
\text { GA }\end{array}$ & $\begin{array}{c}+95 \% \\
\text { GA }\end{array}$ & Q-değeri \\
\hline $\mathrm{H}_{1}$ & $\begin{array}{l}\text { İhracat pazar bilgisi oluş- } \\
\text { turma } \rightarrow \text { İhracat perfor- } \\
\text { mansı }\end{array}$ & 23 & 2,729 & 0,252 & 0,005 & 0,202 & 0,301 & $165,705^{*}$ \\
\hline $\mathrm{H}_{2}$ & $\begin{array}{l}\text { İhracat pazar bilgisi yayılımı } \\
\rightarrow \text { İhracat performansı }\end{array}$ & 23 & 2,729 & 0,185 & 0,007 & 0,127 & 0,243 & $217,679^{*}$ \\
\hline $\mathrm{H}_{3}$ & $\begin{array}{l}\text { İhracat pazarına cevap veri- } \\
\text { lebilirlik } \rightarrow \text { İhracat perfor- } \\
\text { mansı }\end{array}$ & 24 & 2,829 & 0,244 & 0,005 & 0,195 & 0,292 & $163,714^{*}$ \\
\hline \multirow[t]{4}{*}{$\mathrm{H}_{4}$} & $\begin{array}{l}\text { Öznel/nesnel ölçüm birim- } \\
\text { leri x İhracat pazar yönelimi } \\
\rightarrow \text { İhracat performansı }\end{array}$ & & & & & & & $18,974 *$ \\
\hline & Öznel ölçüm birimi & 46 & 2,832 & 0,261 & 0,003 & 0,232 & 0,290 & \\
\hline & Nesnel ölçüm birimi & 18 & 1,328 & 0,169 & 0,010 & 0,093 & 0,243 & \\
\hline & Karma ölçüm birimi & 6 & 372 & 0,128 & 0,004 & 0,070 & 0,186 & \\
\hline \multirow[t]{3}{*}{$\mathrm{H}_{5}$} & $\begin{array}{l}\text { Ekonomik/ekonomik olma- } \\
\text { yan ölçüm birimleri x İhra- } \\
\text { cat pazar yönelimi } \rightarrow \text { İhra- } \\
\text { cat performansı }\end{array}$ & & & & & & & $4,759^{*}$ \\
\hline & Ekonomik ölçüm birimi & 48 & 2,286 & 0,205 & 0,004 & 0,168 & 0,240 & \\
\hline & $\begin{array}{l}\text { Ekonomik olmayan öl- } \\
\text { çüm birimi }\end{array}$ & 22 & 2,049 & 0,276 & 0,006 & 0,223 & 0,327 & \\
\hline \multirow[t]{3}{*}{$\mathrm{H}_{6}$} & $\begin{array}{l}\text { Ekonominin gelişmişlik dü- } \\
\text { zeyi x İhracat pazar yöne- } \\
\text { limi } \rightarrow \text { İhracat performansı }\end{array}$ & & & & & & & 1,807 \\
\hline & Gelişmiş ülkeler & 28 & 2,074 & 0,252 & 0,006 & 0,202 & 0,300 & \\
\hline & Gelişmekte olan ülkeler & 42 & 1,538 & 0,210 & 0,004 & 0,172 & 0,246 & \\
\hline
\end{tabular}

$* p<0,05$ düzeyinde anlamlıdır.

Son olarak, $\mathrm{H}_{6}{ }^{\prime}$ da önerildiğinin aksine, ihracat pazar yönelimi ile ihracat performansı arasındaki ilişki, ülkelerin gelişmişlik düzeylerine göre istatistiksel olarak anlamlı bir farklılık ortaya koymamaktadır ( $Q$-değeri $(1 s d)=1,807(p=0,179)$ ). Bu bulgu, daha önce Ellis (2006) tarafından yapılmış olan ve gelişmiş ülkelerde pazar yöneliminin performans üzerinde daha büyük bir etki yarattığını ortaya koyan meta-analitik sonuçlardan farklı olarak, ihracat pazar yöneliminin performansı arttırmada sadece gelişmiş ülkelerde değil, aynı zamanda gelişmekte olan ekonomilerde de benzer derecede önemli bir rol oynadığını göstermektedir. Bu sonuç, gelişmiş olan ül- 
kelerde faaliyet gösteren firmaların aksine, gelişmekte olan ekonomilerde firmaların somut kaynakları elde etmede daha çok zorluklarla karşılaşmalarına ve dolayısı ile performanslarını arttırmada ihracat pazar yönelimine daha çok bağımlı olmaları ile açıklanabilir (Birru vd., 2018; Boso vd., 2012).

\section{Sonuç, Öneriler ve Kısıtlar}

İlgili literatürde ihracat pazar yönelimi ile ihracat performansı arasındaki ilişkiyi inceleyen çok fazla sayıda araştırma olduğundan, bu meta-analiz çalışması, daha önceden bu alanda yapılmış olan tüm araştırmaları bir araya getirmeyi ve bu ilişki üzerinde önemli rol oynayabileceği düşünülen olası moderatörleri de ortaya koyarak, tüm ampirik bulguları sayısal olarak sentezlemeyi amaçlamıştır. İlk olarak, bu çalışmada açığa çıkan bulgular ışığında ihracat pazar bilgisi oluşturmanın ihracat performansını arttırmada, diğer ihracat pazar yönelimi boyutlarına kıyasla, daha önemli bir rol oynadığını söylemek mümkündür (Örn: Cadogan vd., 2009; Kayabasi ve Mtetwa, 2016). Diğer bir deyişle, firmaların ihracat pazarlarındaki müşterileri, rakipleri ve performanslarını etkileyebilecek dış etkenler üzerine bir ön araştırma yaparak gerekli bilgiler edinmesi, onlara yabancı oldukları uluslararası pazarları analiz ederek daha doğru stratejiler geliştirebilmesi ve dolayısı ile de ihracat performans göstergelerini iyileştirebilmeleri açısından çok büyük önem taşımaktadır (Cadogan vd., 2003; Kohli vd., 1993; Murray vd., 2007; Rose ve Shoham, 2002).

Buna ek olarak, sentezlenmiş olan bulgular ihracat performansını öznel ölçüm birimleriyle değerlendiren araştırmalarda, ihracat pazar yönelimli firmaların performanslarını, nesnel ölçüm birimiyle ölçen çalışmalara oranla daha fazla geliştirebildiklerini doğrulamaktadır (Örn: Chung, 2012; Lin vd., 2014; Murray vd., 2007). Bu sonucu, performansı değerlendirirken yönetici algılarına yönelik birden fazla değişkene ait soruların sorulmasının ortak yöntem varyansını arttırmasının da tetiklediği düşünülmektedir (Chang vd., 2010; Doty ve Glick, 1998). Bunun yanı sıra, meta-analitik sonuçlar ihracat pazar yöneliminin yüksek olmasının, stratejik performans ya da pazar performansı gibi ekonomik olmayan performans göstergeleri üzerinde daha etkili olduğunu da göstermektedir (Örn: Kayabasi ve Mtetwa, 2016; Sundqvist vd., 2000).

Buradan yola çıkarak, firmaların ihracat pazarlarındaki müşterinin değişen ihtiyaç ve tercihleri, rakiplerinin eylemleri ve onların satış ve stratejilerini etkileyebileceği düşünülen çevresel faktörler ile ilgili güncel pazar bilgileri elde etmeye, bu edindikleri bilgileri paylaşmaya ve doğru bir şekilde yorumlamaya yönelmelerinin, onların uluslararası pazarda daha stratejik kararlar alabilmelerine, uygun stratejileri belirleyebilmelerine ve bu doğrultuda rekabet avantajı kazanarak, pazar odaklı ve stratejik performanslarını geliştirebilmelerine yardımcı olmaktadır (Cadogan vd., 2003; Ketchen vd., 2007; Javalgi vd., 2005). Son olarak, araştırma bulguları hem gelişmiş hem de gelişmekte olan ekonomilerde, ihracat pazar yönelimli olmanın firmalar için müşteri ve pazar ihtiyaçlarını öngörme ve sonuç olarak ihracat performansını geliştirme konusundaki önemini vurgulamakta ve ortaya çıkarmaktadır (Birru vd., 2018; Pascucci vd., 2016).

Bu meta-analiz çalışması ilgili literatüre dört farklı şekilde katkıda bulunmaktadır. İlk olarak, bu çalışma, literatürde birbirinden bağımsız araştırmalarda ortaya koyulan ampirik bulguları, sistematik bir şekilde bir araya toplayarak bütüncül bir yaklaşım ile sayısallaştırarak sentezlemiştir. Ayrıca, bu meta-analiz çalışmasında, ihracat pazar yöneliminin boyutları ayrı ayrı ele alınarak, bu boyutlardan ihracat pazar bilgisi oluşturmanın, ihracat performansı üzerinde diğer boyutlar ile karşılaştırıldığında daha büyük bir etkisi olduğu ortaya konulmaktadır. Buna ilaveten, ihracat performansının öznel ve ekonomik olmayan ölçüm birimleriyle değerlendirilmesinin, ihracat pazar yönelimi ile ihracat performansı arasındaki ilişkinin gücünü arttıracağı önemle 
vurgulanmaktadır. Bunların dışında, ihracat pazar yönelimli firmaların hem gelişmiş hem de gelişmekte olan ülkelerde, ihracat performansını arttırmada benzer bir rol oynadığını göstermektedir.

Bu çalışmanın sonuçları, yöneticiler açısından da çok önemli çıkarımlar sunmaktadır. İlk olarak, pazar yönelimli olmak, firmalara gelecekteki pazar fırsatlarını ve tehditlerini öngörmede yardımcı olacağı ve müşterilerin ihtiyaçları konusunda daha güvenilir tahminler sunacağı için yöneticiler için yol gösterici niteliği taşıyacaktır (Day, 1999). Özellikle, sürekli değişmekte olan ve çok fazla bilgi sahibi olunmayan uluslararası pazarlar hakkında, müşteri, rakipler ve çevresel faktörler ile ilgili güncel pazar bilgisi edinerek, buna uygun stratejiler belirlemek, ihracat performansını arttırmada yöneticilere yardımcı olacaktır (Cadogan vd., 2002). Bunun yanı sıra, sadece ihracat pazar yönelimli olmanın yeterli olmadı̆̆ı gösterilmiş, ayrıca firmaların pazar hakkında güncel bilgileri toplamasının, bu edindikleri bilgileri doğru bir şekilde yorumlayabilmesinin ve uygun stratejiler ile karşılık verebilmesinin öneminin de altı çizilmiştir (Kohli ve Jaworski, 1990; Chung, 2012). Ayrıca, yöneticilerin ihracat pazar yönelimli bir firma olmanın öncelikle onların stratejik ve pazar performansını iyileştirmeye yardımcı olacağının, fakat uzun vadede finansal performans üzerinde de olumlu etkileri olacağının farkında olması gerekmektedir (Ketchen vd., 2007).

Ancak her çalışmada olduğu gibi, bu araştırma da kendi içerisinde bazı kısıtları barındırmaktadır. Bu meta-analitik çalışmada, ilgili literatürdeki tüm ampirik bulgular, çalışmalarda korelasyon katsayısının raporlanmaması ya da ona dönüştürülebilecek uygun istatistiksel verilere ulaşılamaması gibi sebeplerden ötürü, analizlere dahil edilememiştir (Hunter ve Schmidt, 2004). Buna ek olarak, diğer bir önemli kısıt, aynı ülkede yürütülmüş olan çalışmalarda araştırmacılar o ülkedeki başarılı örnekler ile görüşmeye daha eğilimli olacağından, aynı firmaların birden fazla çalışmanın örneklemi içerisinde yer alma riskini oluşturmaktadır. Bununla birlikte, gelecek araştırmacıların, çok fazla çalışılmış olan ihracat performansı çıktıları yerine, ihracat pazar yöneliminin diğer çıtılırı üzerine yoğunlaşmaları önerilmektedir (Örn: strateji ve inovasyon ile ilişkili çıktılar). Ayrıca, bu çalışmada davranışsal yaklaşıma göre incelenen ihracat pazar yöneliminin, gelecekteki araştırmalarda kültürel açıdan ele alınmasının (müşteri yönelimi, rakip yönelimi, vb.), önemli içgörüler ortaya koyacağı düşünülmektedir. Illaveten, ihracat pazar yönelimi ve ihracat performansı arasındaki ilişki üzerinde etkili olabileceği düşünülen firma büyüklüğü, faaliyet gösterdiği sektör, gelire dayalı performans ve maliyete dayalı performans göstergeleri gibi diğer moderatörlerin etkilerinin de incelenmesinin gelecek araştırmalara ışı tutması beklenmektedir. 


\section{Kaynaklar}

Acosta, Alexandra Solano; Crespo, Ángel Herrero; Agudo, Jesús Collado (2018), "Effect of Market Orientation, Network Capability and Entrepreneurial Orientation on International Performance of Small and Medium Enterprises (SMEs)", International Business Review, Vol. 27, No. 6: 1128-1140.

Akyol, Ayşe; Akehurst, Gary (2003), "An Investigation of Export Performance Variations Related to Corporate Export Market Orientation", European Business Review, Vol. 15, No. 1: 5-19.

Birleşmiş Milletler (2018), "World Economic Situation Prospects". https://www.un.org/development/desa/dpad/wpcontent/uploads/sites/45/publication/WESP2018_Full_Web-1.pdf, (Erişim: 11.12.2018).

Birru, Worku Tuffa; Runhaar, Piety; Zaalberg, Ruud; Lans, Thomas; Mulder, Martin (2018), "Explaining Organizational Export Performance by Single and Combined International Business Competencies", Journal of Small Business Management, Vol. XX, No. X: XX-XX.

Borenstein, Michael; Hedges, Larry V.; Higgins, Julian P.T.; Rothstein, Hannah R. (2009), Introduction to Meta-Analysis, UK: John Wiley \& Sons.

Boso, Nathaniel; Annan, Jonathan; Adeleye, Ifedapo; Iheanachor, Nkemdilim; Narteh, Bedman (2018), "Examining the Paths from Export Strategic Orientations to Export Performance: The Mediating Role of Export Resource Transformation Capability", Thunderbird International Business Review, Vol. 60, No. 2: 207-230.

Boso, Nathaniel; Cadogan, John W.; Story, Vicky M. (2012), "Entrepreneurial Orientation and Market Orientation as Drivers of Product Innovation Success: A Study of Exporters From A Developing Economy", International Small Business Journal, Vol. 31, No. 1: 57-81.

Cadogan, John W.; Cui, Charles; Li, Erik Kwok Yeung (2003), "Export Market-Oriented Behavior and Export Performance: The Moderating Roles of Competitive Intensity and Technological Turbulence", International Marketing Review, Vol. 20, No. 5: 493-513.

Cadogan, John W.; Diamantopoulos, Adamantios; De Mortanges, Charles Pahud (1999), “A Measure of Export Market Orientation: Scale Development and Cross-Cultural Validation", Journal of International Business Studies, Vol. 30, No. 4: 689-707.

Cadogan, John W.; Diamantopoulos, Adamantios; Siguaw, Judy A. (2002), “Export Market-Oriented Activities: Their Antecedents and Performance Consequences", Journal of International Business Studies, Vol. 33, No. 3: 615-626.

Cadogan, John W.; Kuivalainen, Olli; Sundqvist, Sanna (2009), "Export Market-Oriented Behavior and Export Performance: Quadratic and Moderating Effects under Differing Degrees of Market Dynamism and Internationalization", Journal of International Marketing, Vol. 17, No. 4: 71-89.

Cadogan, John W.; Paul, Nicola J.; Salminen, Risto T.; Puumalainen, Kaisu; Sundqvist, Sanna (2001), "Key Antecedents to "Export" Market-Oriented Behaviors: A Cross-National Empirical Examination", International Journal of Research in Marketing, Vol. 18, No. 3: 261-282.

Cadogan, John W.; Sundqvist, Sanna; Puumalainen, Kaisu; Salminen, Risto T. (2012), "Strategic Flexibilities and Export Performance: The Moderating Roles of Export Market-Oriented Behavior and the Export Environment", European Journal of Marketing, Vol. 46, No. 10: 1418-1452.

Cano, Cynthia Rodriguez; Carrillat, Francois A.; Jaramillo, Fernando (2004), “A Meta-Analysis of the Relationship between Market Orientation and Business Performance: Evidence from Five Continents", International Journal of Research in Marketing, Vol. 21, No. 2: 179-200.

Chakravarthy, Balaji S. (1986), "Measuring Strategic Performance”, Strategic Management Journal, Vol. 7, No. 5: 437458.

Chang, Yong-Sheng; Fang, Shyh-Rong (2015), "Enhancing Export Performance for Business Markets: Effects of Interorganizational Relationships on Export Market Orientation (EMO)", Journal of Business-to-Business Marketing, Vol. 22, No. 3: 211-228.

Chang, Woojung; Franke, George R.; Butler, Timothy D.; Musgrove, Carolyn F.; Ellinger, Alexander E. (2014), “Differential Mediating Effects of Radical and Incremental Innovation on Market Orientation-Performance Relationship: A Meta-Analysis", Journal of Marketing Theory and Practice, Vol. 22, No. 3: 235-250.

Chang, Sea-Jin; Van Witteloostuijn, Arjen; Eden, Lorraine (2010), "From The Editors: Common Method Variance in International Business Research", Journal of International Business Studies, Vol. 41, No. 2: 178-184.

Chung, Henry F.L. (2012), "Export Market Orientation, Managerial Ties, and Performance", International Marketing Review, Vol. 29, No. 4: 403-423. 


\section{Eskişehir Osmangazi Üniversitesi IïB Dergisi}

Cooper, Harris; Hedges, Larry V.; Valentine, Jeffrey C. (2009), The Handbook of Research Synthesis and Meta-Analysis, New York: Russell Sage Foundation.

Covin, Jeffrey G.; Prescott, John E.; Slevin, Dennis P. (1990), "The Effects of Technological Sophistication on Strategic Profiles, Structure and Firm Performance", Journal of Management Studies, Vol. 27, No. 5: 485-510.

Cronin Jr, Joseph J.; Page Jr, Thomas J. (1988), "An Examination of the Relative Impact of Growth Strategies on Profit Performance", European Journal of Marketing, Vol. 22, No. 1: 57-68.

Day, George S. (1999), "Misconceptions About Market Orientation”, Journal of Market-Focused Management, Vol. 4, No.1: 5-16.

Deshpandé, Rohit; Farley, John U.; Webster Jr, Frederick E. (1993), “Corporate Culture, Customer Orientation, and Innovativeness in Japanese Firms: A Quadrad Analysis", Journal of Marketing, Vol. 57, No. 1: 23-37.

Dess, Gregory G.; Robinson Jr, Richard B. (1984), “Measuring Organizational Performance in the Absence of Objective Measures: The Case of the Privately-Held Firm and Conglomerate Business Unit", Strategic Management Journal, Vol. 5, No. 3: 265-273.

Diamantopoulos, Adamantios; Hart, Susan (1993), "Linking Market Orientation and Company Performance: Preliminary Evidence on Kohli and Jaworski's Framework", Journal of Strategic Marketing, Vol. 1, No. 2: 93-121.

Doty, D. Harold; Glick, William H. (1998), “Common Methods Bias: Does Common Methods Variance Really Bias Results?”, Organizational Research Methods, Vol. 1, No. 4: 374-406.

Doyle, Peter; Wong, Veronica (1998), "Marketing and Competitive Performance: An Empirical Study", European Journal of Marketing, Vol. 32, No. 5/6: 514-535.

Duval, Sue; Tweedie, Richard (2000), "A Nonparametric "Trim And Fill" Method of Accounting For Publication Bias in Meta-Analysis", Journal of the American Statistical Association, Vol. 95, No. 449: 89-98.

Ellis, Paul D. (2005), "Market Orientation and Marketing Practice in a Developing Economy", European Journal of Marketing, Vol. 39, No. 5/6: 629-645.

Ellis, Paul D. (2006), "Market Orientation and Performance: A Meta-Analysis and Cross-National Comparisons", Journal of Management Studies, Vol. 43, No. 5: 1089-1107.

Finkelstein, Lisa M.; Burke, Michael J.; Raju, Nambury S. (1995), "Age Discrimination in Simulated Employment Contexts: An Integrative Analysis", Journal of Applied Psychology, Vol. 80, No. 6: 652-663.

Geyskens, Inge; Steenkamp; Jan-Benedict E.; Kumar, Nirmalya (1998), "Generalizations About Trust in Marketing Channel Relationships Using Meta-Analysis", International Journal of Research in Marketing, Vol. 15, No. 3: $223-248$.

Geyskens, Inge; Krishnan, Rekha; Steenkamp, Jan-Benedict E.M.; Cunha, Paulo V. (2009), "A Review and Evaluation of Meta-Analysis Practices in Management Research", Journal of Management, Vol. 35, No. 2: 393-419.

Glass, Gene V. (1976), "Primary, Secondary, and Meta-Analysis of Research", Educational Researcher, Vol. 5, No. 10: 38.

Golden, Brian R. (1992), "SBU Strategy and Performance: The Moderating Effects of the Corporate-SBU Relationship", Strategic Management Journal, Vol. 13, No. 2: 145-158.

Govindarajan, Vijay (1988), “A Contingency Approach to Strategy Implementation at the Business-Unit Level: Integrating Administrative Mechanisms With Strategy", Academy of Management Journal, Vol. 31, No. 4: 828-853.

Greenley, Gordon E. (1995), "Market Orientation and Company Performance: Empirical Evidence From UK Companies", British Journal of Management, Vol. 6, No. 1: 1-13.

Grewal, Dhruv; Puccinelli, Nancy; Monroe, Kent B. (2018), "Meta-Analysis: Integrating Accumulated Knowledge”, Journal of the Academy of Marketing Science, Vol. 46, No. 1: 9-30.

Grinstein, Amir (2008a), "The Effect of Market Orientation and Its Components on Innovation Consequences: A MetaAnalysis", Journal of the Academy of Marketing Science, Vol. 36, No. 2: 166-173.

Grinstein, Amir (2008b), "The Relationships between Market Orientation and Alternative Strategic Orientations: A Meta-Analysis", European Journal of Marketing, Vol. 42, No. 1/2: 115-134.

Han, Jim K.; Kim, Namwoon; Srivastava, Rajendra K. (1998), “Market Orientation and Organizational Performance: Is Innovation a Missing Link?", Journal of Marketing, Vol. 62, No. 4: 30-45.

Harris, Lloyd C. (2001), “Market Orientation and Performance: Objective and Subjective Empirical Evidence From UK Companies", Journal of Management Studies, Vol. 38, No. 1: 17-43. 
Hart, Susan; Tzokas, Nikolaos (1999), "The Impact of Marketing Research Activity on SME Export Performance: Evidence from the UK", Journal of Small Business Management, Vol. 37, No. 2: 63-75.

He, X.; Brouthers, Keith D.; Filatotchev, Igor (2013), "Resource-Based and Institutional Perspectives on Export Channel Selection and Export Performance", Journal of Management, Vol. 39, No. 1: 27-47.

Henard, David H.; Szymanski, David M. (2001), "Why Some New Products Are More Successful Than Others", Journal of Marketing Research, Vol. 38, No. 3: 362-375.

Homburg, Christian; Pflesser, Christian (2000), “A Multiple-Layer Model of Market-Oriented Organizational Culture: Measurement Issues and Performance Outcomes", Journal of Marketing Research, Vol. 37, No. 4: 449-462.

Hooley, Graham; Cox, Tony; Fahy, John; Shipley, David; Beracs, József; Fonfara, Krzysztof; Snoj, Boris (2000), “Market Orientation in the Transition Economies of Central Europe: Tests of the Narver and Slater Market Orientation Scales", Journal of Business Research, Vol. 50, No. 3: 273-285.

Huber, George P. (1991), “Organizational Learning: The Contributing Processes and the Literatures”, Organization Science, Vol. 2, No. 1: 88-115.

Hunter, John E.; Schmidt, Frank L. (2004), Methods of Meta-Analysis: Correcting Error and Bias in Research Findings, Thousand Oaks, US: Sage Publications, Inc.

Hurley, Robert F.; Hult, Tomas M. (1998), “Innovation, Market Orientation, and Organizational Learning: An Integration and Empirical Examination", Journal of Marketing, Vol. 62, No. 3: 42-54.

Janiszewski, Chris; Noel, Hayden; Sawyer, Alan G. (2003), "A Meta-Analysis of the Spacing Effect in Verbal Learning: Implications for Research on Advertising Repetition and Consumer Memory", Journal of Consumer Research, Vol. 30, No. 1: 138-149.

Javalgi, Rajshekhar G.; Whipple, Thomas W.; Ghosh, Amit K.; Young, Robert B. (2005), "Market Orientation, Strategic Flexibility, and Performance: Implications for Services Providers", Journal of Services Marketing, Vol. 19, No. 4: 212-221.

Jaworski, Bernard J.; Kohli, Ajay K. (1993), “Market Orientation: Antecedents and Consequences”, Journal of Marketing, Vol. 57, No. 3: 53-70.

Katsikeas, Constantine S.; Leonidou, Leonidas C.; Morgan, Neil A. (2000), “Firm-Level Export Performance Assessment: Review, Evaluation, and Development", Journal of the Academy of Marketing Science, Vol. 28, No. 4: 493-511.

Kayabasi, Aydin; Mtetwa, Thandiwe (2016), "Impact of Marketing Effectiveness and Capabilities, and Export Market Orientation on Export Performance: Evidence From Turkey", European Business Review, Vol. 28, No. 5: 532-559.

Ketchen Jr, David J.; Hult, G. Tomas M.; Slater, Stanley F. (2007), "Toward Greater Understanding of Market Orientation and The Resource-Based View", Strategic Management Journal, Vol. 28, No. 9: 961-964.

Kirca, Ahmet H.; Jayachandran, Satish; Bearden, William O. (2005), "Market Orientation: A Meta-Analytic Review and Assessment of Its Antecedents and Impact on Performance", Journal of Marketing, Vol. 69, No. 2: 24-41.

Kohli, Ajay K.; Jaworski, Bernard J. (1990), “Market Orientation: The Construct, Research Propositions, and Managerial Implications". Journal of Marketing, Vol. 54, No. 2: 1-18.

Kohli, Ajay K.; Jaworski, Bernard J.; Kumar, Ajith (1993), “MARKOR: A Measure of Market Orientation”, Journal of Marketing Research, Vol. 30, No. 4: 467-477.

Kumar, Kamalesh; Subramanian, Ram; Yauger, Charles (1998), "Examining the Market Orientation-Performance Relationship: A Context-Specific Study", Journal of Management, Vol. 24, No. 2: 201-233.

Lengler, Jorge F. B.; Sousa, Carlos M. P.; Perin, Marcelo Gattermann; Sampaio, Cláudio Hoffmann; Martínez-López, Francisco J. (2016), "The Antecedents of Export Performance of Brazilian Small and Medium-Sized Enterprises (SMEs): The Non-Linear Effects of Customer Orientation", International Small Business Journal, Vol. 34, No. 5: 701727.

Lin, Ku-Ho; Huang, Kuo-Feng; Peng, Yao-Ping (2014), "Impact of Export Market Orientation on Export Performance: A Relational Perspective”, Baltic Journal of Management, Vol. 9, No. 4: 403-425.

Lipsey, Mark W.; Wilson, David B. (2001), Practical Meta-Analysis, Thousand Oaks, US: Sage Publications, Inc.

Makri, Katerina; Theodosiou, Marios; Katsikea, Evangelia (2017), “An Empirical Investigation of the Antecedents and Performance Outcomes of Export Innovativeness", International Business Review, Vol. 26, No. 4: 628-639.

Mavondo, Felix T.; Farrell, Mark A. (2000), "Measuring Market Orientation: Are There Differences between Business Marketers and Consumer Marketers?", Australian Journal of Management, Vol. 25, No. 2: 223-244. 


\section{Eskişehir Osmangazi Üniversitesi IïBF Dergisi}

Murray, Janet Y.; Gao, Gerald Yong; Kotabe, Masaaki (2011), “Market Orientation and Performance of Export Ventures: The Process through Marketing Capabilities and Competitive Advantages", Journal of the Academy of Marketing Science, Vol. 39, No. 2: 252-269.

Murray, Janet Y.; Gao, Gerald Yong; Kotabe, Masaaki; Zhou, Nan (2007), “Assessing Measurement Invariance of Export Market Orientation: A Study of Chinese and Non-Chinese Firms in China", Journal of International Marketing, Vol. 15, No. 4: 41-62.

Narver, John C.; Slater, Stanley F. (1990), "The Effect of a Market Orientation on Business Profitability", Journal of Marketing, Vol. 54, No, 2: 20-35.

Navarro-García, Antonio; Arenas-Gaitán, Jorge; Rondán-Cataluña, F. Javier (2014), “External Environment and the Moderating Role of Export Market Orientation", Journal of Business Research, Vol. 67, No. 5: 740-745.

Orwin, Robert G. (1983), “A Fail-Safe N for Effect Size in Meta-Analysis”, Journal of Educational Statistics, Vol. 8, No. 2: 157-159.

Özsomer, Ayşegül ve Gençtürk, Esra (2003), “A Resource-Based Model of Market Learning in the Subsidiary: The Capabilities of Exploration and Exploitation", Journal of International Marketing, Vol. 11, No. 3: 1-29.

Palmatier, Robert W.; Dant, Rajiv P.; Grewal, Dhruv; Evans, Kenneth R. (2006), "Factors Influencing the Effectiveness of Relationship Marketing: A Meta-Analysis”, Journal of Marketing, Vol. 70, No. 4: 136-153.

Pascucci, Federica; Bartoloni, Sara; Gregori, Gian Luca (2016), “Export Market Orientation and International Performance in the Context of SMEs", Journal of Small Business and Entrepreneurship, Vol. 28, No. 5: 361-375.

Robinson Jr, Richard B.; Pearce, John A. (1988), "Planned Patterns of Strategic Behavior and Their Relationship to Business-Unit Performance", Strategic Management Journal, Vol. 9, No. 1: 43-60.

Rose, Gregory M.; Shoham, Aviv (2002), "Export Performance and Market Orientation: Establishing an Empirical Link", Journal of Business Research, Vol. 55, No. 3: 217-225.

Rosenthal, Robert (1979), "The File Drawer Problem and Tolerance for Null Results", Psychological Bulletin, Vol. 86, No. 3: 638-641.

Shoham, Aviv; Rose, Gregory M.; Kropp, Fredric (2005), "Market Orientation and Performance: A Meta-Analysis", Marketing Intelligence \& Planning, Vol. 23, No. 5: 435-454.

Shoham, Aviv; Ruvio, Ayalla Ruvio; Vigoda-Gadot, Eran; Schwabsky, Nitza (2006), "Market Orientations in the Nonprofit and Voluntary Sector: A Meta-Analysis of Their Relationships with Organizational Performance", Nonprofit and Voluntary Sector Quarterly, Vol. 35, No. 3: 453-476.

Slater, Stanley F.; Narver, John C. (1994), "Does Competitive Environment Moderate the Market Orientation-Performance Relationship?", Journal of Marketing, Vol. 58, No. 1: 46-55.

Slater, Stanley F.; Narver, John C. (1995), “Market Orientation and the Learning Organization”, Journal of Marketing, Vol. 59, No. 3: 63-74.

Sørensen, Hans Eibe (2009), "Why Competitors Matter for Market Orientation", European Journal of Marketing, Vol. 43, No. 5/6: 735-761.

Sundqvist, Sauna; Puumalainen, Kaisu; Salminen, Risto T.; Cadogan, John W. (2000), "The Interaction Between Market Orientation, Industry Environment and Business Success: Evidence from an Exporting Context", Australasian Marketing Journal, Vol. 8, No. 1: 55-69.

Szymanski, David M.; Henard, David H. (2001), "Customer Satisfaction: A Meta-Analysis of the Empirical Evidence", Journal of the Academy of Marketing Science, Vol. 29, No. 1: 16-35.

Venkatraman, N.; Ramanujam, Vasudevan (1986), "Measurement of Business Performance in Strategy Research: A Comparison of Approaches", Academy of Management Review, Vol. 11, No. 4: 801-814.

Yeoh, Poh-Lin (2000), "Information Acquisition Activities: A Study of Global Start-Up Exporting Companies", Journal of International Marketing, Vol. 8, No. 3: 36-60. 


\section{Extended Summary}

\section{The Influence of the Dimensions of Export Market Orientation on Export Performance: A Meta-Analysis Study}

In recent years, firms face with the challenge of continuous improvement for their products/services owing to the dynamic and uncertain nature of markets (Hurley and Hunt, 1998). In response, firms are required to be market-oriented via following and gathering the most recent and reliable knowledge concerning the changes in customer demands and preferences within the market (Özsomer and Gençtürk, 2003). However, the concept of market orientation even becomes more critical for firms operating in foreign markets due to the fact that there exist several differences between home and host markets in terms of economic, socio/cultural, geographic, and political/legal environments (Murray at al., 2011). In that vein, exporting firms necessitate putting a special emphasis on gathering current information, understanding the shifts in foreign customer demands, and evaluating the competitor activities with an intent to adapt their strategies and achieve success in foreign markets (Cadogan et al., 2003; He et al., 2013). In this sense, this study endeavors to quantitatively synthesize all empirical findings examining the link between export market orientation (EMO) dimensions and export performance. To address the main objective of the research, the present study aims to assess: (a) a meta-analytic evaluation between the dimensions of export market orientation (i.e., export market intelligence generation, export market intelligence dissemination, and export market responsiveness) and export performance; (b) the moderator roles of performance measurements (i.e., objective/subjective measurements, economic/non-economic measurements) and the economic development level of countries (i.e., developing and developed countries) in the link between EMO dimensions and export performance; and (c) theoretical and practical insights related to export market orientation and its performance implications.

In the pertinent literature, there appears to be two different approaches that conceptualize market orientation as a behavioral and cultural concept (Homburg and Pflesser, 2000). While the former defines market orientation as an organizational activity that focuses on market knowledge generation and dissemination (e.g., Kohli and Jaworski, 1990), the latter advocates that market orientation acts as a facilitator in creating and accelerating customer value process via embracing the norms and beliefs of organizational culture (e.g., Deshpandé et al., 1993; Narver and Slater, 1990). With regard to the behavioral approach, firms with higher export market orientation in fact demonstrates the three dimensions of the phenomenon: "export market intelligence generation", "export market intelligence dissemination", and "export market responsiveness" (Cadogan et al., 1999; Cadogan et al., 2009). Even though several researchers examine export market orientation in the extant literature, many scholars emphasize the importance of addressing the different impacts of these distinct EMO dimensions on performance outcomes (Chung, 2012, Sørensen, 2009). In this sense, a wide variety of studies reveal inconsistent and fragmented findings related to the differential effects of EMO dimensions on export performance in the pertinent literature (e.g., Murray et al., 2007; Rose and Shoham, 2002). In line with this, the current study developed and tested six different hypotheses in an attempt to aggregate all empirical evidence in the literature.

Methodologically, first of all, the inclusion criteria were specified to find out the eligible studies. Thereafter, employing both electronic and manual search methods, 38 empirical articles on the subject were gathered; of these 28 were eliminated because of the failure to satisfy the inclusion criteria. In total, 70 effects dependent upon more than 2,800 firms $(N=2,829)$ were calculated in this meta-analytic review. Besides, the relevant articles published between 2000 and 2018 were subject to content analysis based on a coding scheme that aims to codify the main characteristics of the studies, their methodological perspectives, and the moderating factors. Following this, in order to evaluate the robustness of the meta-analytic findings, publication bias was assessed by applying to both statistical (i.e., (1) Rosenthal's (1979) 'file drawer' method, (2) Orwin's (1983) 'failsafe N' (set to 0.05), and (3) the 'trim-and-fill' method of Duval and Tweedie (2000)), and graphical methods (i.e., the funnel plot), all of which confirmed that publication bias does not constitute a concern for this meta-analytic study. In addition, sensitivity analysis was performed, and heterogeneity test was made, demonstrating that the variations of the relevant studies covered in the meta-analysis are heterogeneously distributed, and potential moderators are likely to be exist in this meta-analytic investigation. Accordingly, the random-effects model was selected.

The findings of the meta-analytic review indicate that export market intelligence generation, dissemination, and responsiveness, all dimensions of export market orientation give rise to export performance. However, in respect of the meta-analytic results, compared to other dimensions, export market intelligence generation is more influential on increasing export success. Concerning the moderating roles of measurement factors, the strengths of the linkages between export market orientation and export performance were found to be greater among the studies assessing the export performance construct with subjective and non-economic indicators. As for the moderating impact of contextual factors on the export market orientation - export performance linkage, no significant variations were detected 
Eskişehir Osmangazi Üniversitesi ïBß Dergisi

across countries with different economic development levels. In conclusion, building on the wealth of research investigating the influence of export market orientation on export performance, this meta-analysis considerably contributes to the pertinent literature by quantatively synthesizing prior empirical evidence on the subject and thoroughly examining the roles of potential measurement and contextual moderators. In that vein, this meta-analytic research offers worthwhile theoretical and managerial insights into the understanding of the export market orientation phenomenon. 